\title{
Systematic Reviews on Pharmacological Treatment of Asthma and Chronic Obstructive Pulmonary Disease
}

Gustavo J. Rodrigo, MD

Departamento de Emergencia, Hospital Central de las Fuerzas Armadas, Montevideo, Uruguay

\section{ABSTRACT}

Typically, therapeutic decisions are made on the basis of different relevant pivotal clinical studies. However, these studies often vary in different ways, which can lead to different answers to the same question. Because it is difficult for readers to capture and evaluate all the primary studies, review articles are an important source of summarized evidence on a particular topic. Systematic reviews (SRs) condense the results of available carefully designed healthcare studies and provide a high level of evidence on the effectiveness of healthcare interventions. Thus, the aim of this article is to provide the most updated information on pharmacological treatment of the two most prevalent chronic obstructive airway diseases, bronchial asthma and chronic obstructive pulmonary disease (COPD), from fourteen SRs of randomized controlled trials (RCTs). This review analyses the strengths and weaknesses of each SR in order to evaluate its clinical applicability. (BRN Rev. 2018;4:122-34) Corresponding author: Gustavo J. Rodrigo, gustavo.javier.rodrigo@gmail.com

Key words: Asthma. Chronic obstructive pulmonary disease. Meta-analysis. Systematic review. 


\section{INTRODUCTION}

Chronic obstructive pulmonary diseases (COPD) are leading causes of mortality and morbidity worldwide. Bronchial asthma and COPD are the most frequent entities, affecting an estimated of 358 and 174 million respectively ${ }^{1,2}$.

Today the practice of medicine has become more and more specialized. Thus, the number of published studies has dramatically increased in the biomedical literature ${ }^{3}$. In pulmonary medicine as well as in other areas, therapeutic decisions are made on the basis of different relevant pivotal clinical studies. However, these studies often vary in design, methods, quality, population, outcomes, and interventions, which can lead to different answers to the same question ${ }^{4}$. Since it is difficult for readers to capture and evaluate all the primary studies, review articles are a very important tool. In particular systematic reviews (SRs) summarize the results of available carefully designed published and unpublished healthcare studies and provide a high level of evidence on the effectiveness of healthcare interventions $s^{5,6}$. When possible, authors pool numerical data about effects of the treatment through a process called meta-analysis ${ }^{7,8}$. In this way, SRs can summarize the existing clinical research on a topic and provide a transparent, objective, and replicable framework to evaluate a series of studies as a whole, rather than looking at them in isolation. Additionally, SRs can help in guideline development and support, because they involve searching for, selecting, critically appraising and summarizing the results of primary published and unpublished research ${ }^{9}$. The aim of this article is to provide the most updated information on the pharmacological treatment of asthma and COPD from SRs of randomised controlled trials (RCTs).

\section{METHODS}

We identified published SRs from Medline, Embase, Scopus and the Cochrane Database of Systematic Reviews databases using the terms "Asthma OR COPD AND Meta-Analysis OR Systematic Review". We selected SRs published between January 2015 and November 2017. To be included, SRs had to meet all the following criteria: a) SRs of RCTs without language restriction; b) inclusion of adults ( $\geq 18$ years) with stable asthma or COPD; and c) studies on pharmacological treatment. SRs that could not be examined in full text or published solely in abstract form were excluded. In the case of two or more SRs on the same topic, only the most updated version was considered. The methodological quality of the SRs was assessed using the MeaSurement Tool to Assess systematic Reviews (AMSTAR 2) instrument ${ }^{10}$, that includes 16 items (Fig. 1). The authors propose a scheme for interpreting the confidence of the results according to the weakness detected in different items: thus, SRs can be rated from "high" to "critically low".

\section{MAIN FINDINGS IN ASTHMA}

Eight SRs of RCTs met the entry criteria for asthma (Fig. 2): one was related with the use of inhaled corticosteroid (ICS)/long-acting $\beta_{2}$-agonists (LABA) (fluticasone furoate/vilanterol) $(\mathrm{FF} / \mathrm{VI})$ combination $^{11}$, one related with stepping-down ICS treatment ${ }^{12}$, one with the use of long-acting muscarinic antagonist (LAMA) 


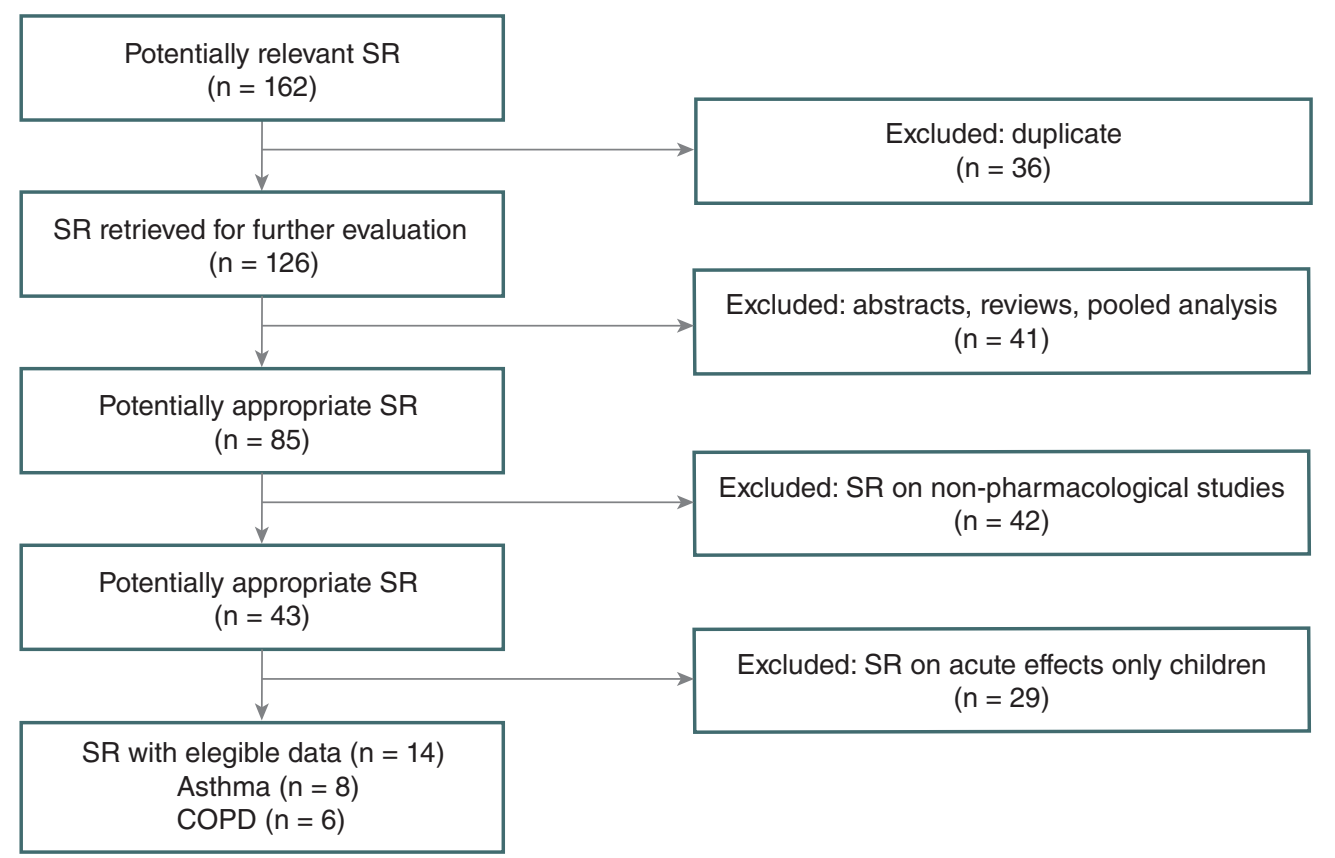

FiguRE 1. Flowchart for identification of systematic reviews selected. COPD: chronic obstructive pulmonary disease; SR: systematic review.

(i.e. tiotropium bromide) $)^{13}$, and five were related to the use of biologic therapies ${ }^{14,18}$. Characteristics of the SRs are shown in table 1. Six SRs display a high confidence in the results ${ }^{11-14,17-18}$, in contrast with two that showed a critically low confidence ${ }^{15-16}$ (Fig. 2).

\section{Inhaled corticosteroid/long-acting $\beta_{2}$-agonists (fluticasone furoate/ vilanterol)}

Dwan et $\mathrm{al}^{11}$ compared the effects of $\mathrm{FF} / \mathrm{VI}$ combination versus placebo, or versus other ICS and/or LABA, on asthma exacerbations and on health-related quality of life in adults and children with chronic asthma. The review was catalogued as high confident (Fig. 2). Although the authors identified 14 studies that met the inclusion criteria, they had very few opportunities to combine results from all the included RCTs. In particular, they found insufficient information to assess whether once-daily FF/VI was better or worse than twice-daily fluticasone propionate/salmeterol (FP/SAL) in terms of efficacy and safety. Although some variables (i.e. pulmonary function tests) showed positive effects for FF/VI, compared with placebo, the variety of comparisons addressed in the included studies did not allow the review's authors to draw firm conclusions. Information was insufficient to assess whether once-daily FF/VI was better or worse than twice-daily FP/SAL. 


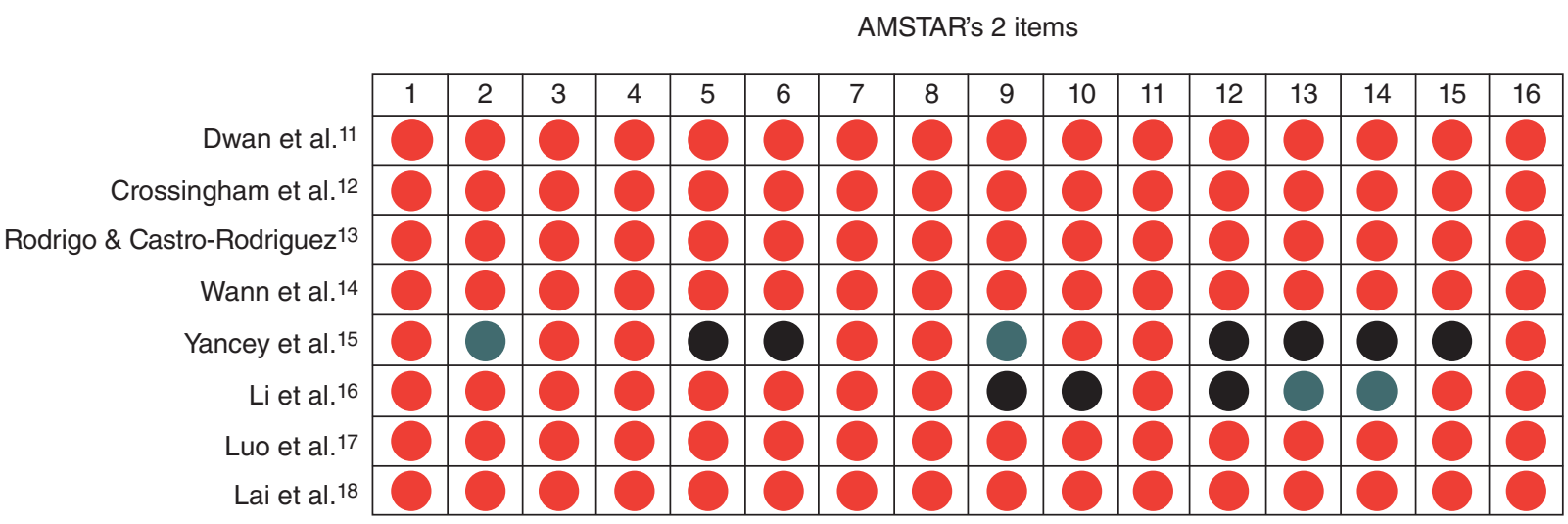

Figure 2. Methodological quality assessment of selected asthma systematic reviews using the Measurement Tool to Assess systematic Reviews (AMSTAR 2) tool*. (with permission form Egger M et al. ${ }^{7}$ ).

\section{Stepping down inhaled corticosteroids treatment}

Crossingham et al. ${ }^{12}$, in a high confidence SR, (Fig. 2) evaluated the evidence for stepping down ICS treatment in adults with well-controlled asthma receiving moderate to high dose of ICS. Although six RCTs were included, meta-analysis was hampered by the small number of studies contributing to each comparison, combined with heterogeneity among the outcomes reported. The authors concluded that the strength of the evidence is not sufficient to determine whether stepping down the dose of ICS is of net benefit for adult patients with well-controlled asthma.

\footnotetext{
* AMSTAR's 2 items are: 1) Did the research questions and inclusion criteria for the review include the components of Patient, Intervention, Control, Outcome (PICO)? 2) Did the report of the review contain an explicit statement that the review methods were established prior to the conduct of the review and did the report justify any significant deviations from the protocol? 3) Did the review authors explain their selection of the study designs for inclusion in the review? 4) Did the review authors use a comprehensive literature search strategy? 5) Did the review authors perform study selection in duplicate? 6) Did the review authors perform data extraction in duplicate? 7) Did the review authors provide a list of excluded studies and justify the exclusions? 8) Did the review authors describe the included studies in adequate detail? 9) Did the review authors use a satisfactory technique for assessing the risk of bias (RoB) in individual studies that were included in the review? 10) Did the review authors report on the sources of funding for the studies included in the review? 11) If meta-analysis was performed did the review authors use appropriate methods for statistical combination of results? 12) If meta-analysis was performed, did the review authors assess the potential impact of RoB in individual studies on the results of the meta-analysis or other evidence synthesis? 13) Did the review authors account for RoB in individual studies when interpreting/discussing the results of the review? 14) Did the review authors provide a satisfactory explanation for, and discussion of, any heterogeneity observed in the results of the review? 15) If they performed quantitative synthesis did the review authors carry out an adequate investigation of publication bias (small study bias) and discuss its likely impact on the results of the review? 16) Did the review authors report any potential sources of conflict of interest, including any funding they received for conducting the review?
} 
TABLE 1. Characteristics of included systematic reviews on asthma

\begin{tabular}{|c|c|c|c|c|c|c|c|c|}
\hline $\begin{array}{l}\text { Systematic } \\
\text { review }\end{array}$ & Origen & $\begin{array}{l}\text { Duration } \\
\text { of studies, } \\
\text { weeks }\end{array}$ & $\begin{array}{l}\text { No of } \\
\text { studies/ } \\
\text { patients }\end{array}$ & $\begin{array}{l}\text { Age } \\
\text { range, } \\
\text { years }\end{array}$ & Asthma severity & $\begin{array}{l}\text { Primary } \\
\text { outcome }\end{array}$ & $\begin{array}{l}\text { Drugs } \\
\text { studied }\end{array}$ & $\begin{array}{c}\text { Sponsored } \\
\text { by the } \\
\text { pharmaceutical } \\
\text { industry }\end{array}$ \\
\hline Dwan et al. ${ }^{11}$ & $\begin{array}{l}\text { United } \\
\text { Kingdom }\end{array}$ & $6-52$ & $14 / 6641$ & $\geq 12$ & Moderate & $\begin{array}{l}\text { EX, HROoL } \\
\text { Adverse events }\end{array}$ & $\mathrm{FF} / \mathrm{VI}$ & No \\
\hline $\begin{array}{l}\text { Crossingham } \\
\text { et al. }^{12}\end{array}$ & $\begin{array}{l}\text { United } \\
\text { Kindom }\end{array}$ & $12-52$ & $6 / 1654$ & $\geq 18$ & Moderate & EX & ICS & No \\
\hline $\begin{array}{l}\text { Rodrigo \& } \\
\text { Castro- } \\
\text { Rodriguez }^{13}\end{array}$ & Uruguay & $4-52$ & $13 / 4966$ & $12-75$ & $\begin{array}{l}\text { Mild }(n=1) \\
\text { Moderate }(n=9) \\
\text { Severe }(n=3)\end{array}$ & $\begin{array}{l}\mathrm{FEV}_{1} \\
\mathrm{PEF}\end{array}$ & Tiotropium & No \\
\hline Wang et al. ${ }^{14}$ & China & $1-56$ & $20 / 7100$ & $12-75$ & $\begin{array}{l}\text { Severe }(n=9) \\
\text { Mild-moderate } \\
(n=4) \\
\text { Eosinophilic/non } \\
\text { eosinophilic }\end{array}$ & $\begin{array}{l}\text { FEV }_{1}, \text { PEF, EX } \\
\text { HRQoL }\end{array}$ & Anti-IL 5 & No \\
\hline Yancey et al. ${ }^{15}$ & $\begin{array}{l}\text { United } \\
\text { Kingdom }\end{array}$ & $\geq 24$ & $4 / 1388$ & $12-82$ & Severe eosinophilic & EX & Mepolizumab & Yes \\
\hline Li et al. ${ }^{16}$ & China & $\geq 12$ & $5 / 1898$ & $12-75$ & Severe eosinophilic & $\mathrm{EX}, \mathrm{FEV}_{1}, \mathrm{ACQ}$ & Reslizumab & No \\
\hline Luo et al. ${ }^{17}$ & China & 8-32 & $8 / 957$ & NA & Moderate to severe & $\begin{array}{l}\text { FEV } \\
\text { PEF } \\
\text { Eosinophils } \\
\text { EX } \\
\text { ACQ }\end{array}$ & Anti-IL 13 & No \\
\hline Lai et al. ${ }^{18}$ & China & $52-60$ & $6 / 2749$ & NA & $\begin{array}{l}\text { Allergic moderate } \\
\text { to severe }\end{array}$ & EX & Omalizumab & No \\
\hline
\end{tabular}

ACQ: asthma control questionnaire; EX: exacerbations; $\mathrm{FEV}_{1}$ : forced volume in the first second; FF/VI: fluticasone furoate/vilanterol; HRQoL: Health-related quality of life; ICS: inhaled corticosteroids; IL: interleukine; NA: data no available; PEF: peak expiratory flow.

\section{Long-acting muscarinic antagonist (tiotropium bromide)}

Rodrigo and Castro-Rodríguez ${ }^{13}$, in a high confidence SR (Fig. 2), assessed the efficacy and safety of tiotropium in symptomatic adults and adolescents with different levels of severity. Three different therapeutic protocols were identified. Tiotropium as an add-on to ICS showed statistically and clinically significant increases in morning and evening peak expiratory flow (PEF) (mean difference $[\mathrm{MD}]=22 \mathrm{~L} / \mathrm{min}$ and $25 \mathrm{~L} / \mathrm{min}$ respectively) and in forced expiratory volume in the first second $\left(\mathrm{FEV}_{1}\right)$ peak and trough $(\mathrm{MD}=150 \mathrm{~mL}$ and $140 \mathrm{~mL}$ respectively). Also, tiotropium decreased the rate of exacerbations (number needed to treat [NNT]
= 36) and showed a greater likelihood of achieving a minimal clinical important difference (MCID) of $\geq 0.5$ units in asthma control questionnaire $(\mathrm{ACQ})$ score $(\mathrm{NNT}=16)$. The use of tiotropium in poorly controlled patients despite the use of medium to high doses of ICS was not inferior to salmeterol. Finally, the use of tiotropium as an add-on to ICS/SAL combination increased pulmonary function to a clinically significant magnitude ( $\geq 100 \mathrm{~mL})$, reduced asthma exacerbations $(\mathrm{NNT}=17)$, and showed a greater likelihood of achieving a MCID ( $\geq 0.5$ units) in ACQ score (NNT = 8) compared with ICS/ salmeterol. This SR suggests that tiotropium is non-inferior to salmeterol and superior to placebo in patients with moderate-to-severe 
asthma who are not adequately controlled by low to moderate ICS or high doses of ICS plus LABA. Major benefits are concentrated in lung function (all increases achieved the MCID). The effect on asthma control seems clinically significant, in particular when tiotropium was used as an add-on to ICS/SAL combination. Finally, the reduction of asthma exacerbations appears to be moderate.

\section{Anti-interleukin-5 (IL-5) monoclonal antibodies}

Wang et al. ${ }^{14}$ in a high confidence SR (Fig. 2) assessed whether anti-IL-5 monoclonal antibodies therapy is safe and effective in adolescents and adults with mild to severe eosinophilic/non-eosinophilic asthma. Twenty RCTs were selected (nine, five, and six trials used mepolizumab, reslizumab, and benralizumab respectively). Pooled analysis revealed that anti-IL5 therapy was well tolerated and significantly improved $\mathrm{FEV}_{1}(\mathrm{MD}=90 \mathrm{ml}$, $\mathrm{p}=0.0001)$ and the Asthma Quality of Life Questionnaire (AQLQ) score (MD $=0.22$, $\mathrm{p}=0.0001)$, while decreased asthmatic exacerbations (relative risk $[R R]=0.66,95 \%$ confidence interval [CI]: 0.59-0.73, p =0.0001) and blood and sputum eosinophil levels, but yielded no effects in PEF and rescue medication use. However, these results did not reach the MCID ( $\geq 100 \mathrm{ml}$ for $\mathrm{FEV}_{1}$ and $\geq 0.5$ units for the $\left.A Q L Q^{19}\right)$. Moreover, it was not possible to evaluate the clinical relevance of the reduction of asthma exacerbations since the SR authors did not report the NNT. In sum, data do not support the superiority of reslizumab over the remaining anti-IL5. An important limitation of this SR was the manifest heterogeneity of studies (regarding the different agents, doses, and asthma phenotypes), which hinders the applicability of results.

Yancey et al. ${ }^{15}$, in a critically low confidence SR (Fig. 2), assessed the rate of exacerbations requiring hospitalization or an emergency room visit in clinical studies of mepolizumab compared with placebo in patients with severe eosinophilic asthma. This review was sponsored by the pharmaceutical industry. On the basis of four RCTs, the authors found that mepolizumab significantly reduced the rate of exacerbations requiring hospitalization $(\mathrm{RR}=0.49$; 95\% CI: 0.30 to $0.80, \mathrm{p}=0.004$ ) and hospitalization/emergency room visits $(\mathrm{RR}=0.49 ; 95 \%$ CI: 0.33 to $0.73, p=0.001)$ vs. placebo. Significant reductions of the order of $45 \%(\mathrm{NNT}=26)$ and $38 \%(\mathrm{NNT}=22)$ were also observed for the proportion of patients experiencing one or more hospitalization and hospitalization and/ or emergency room visits, respectively. While the authors stated that these results suggest an important clinical benefit for mepolizumab, the clinical relevance that arises from the NNT is probably more modest (more than 20 patients must be treated to prevent one hospitalization or hospitalization and/or emergency room visits).

Li et al. ${ }^{16}$ carried out a critically low confidence SR (Fig. 2) to assess the efficacy and safety of reslizumab in patients with inadequately controlled, eosinophilic asthma. On the basis of 5 RCTs, the authors found statistically significant changes in asthma exacerbations (odds ratio [OR] $=0.46$; 95\% CI: 0.35 to 0.59 ), $\mathrm{FEV}_{1}$ (standardized mean difference [SMD] $=0.16 ; 95 \% \mathrm{CI}: 0.10$ to 0.23 ), and ACQ score $(\mathrm{SMD}=-0.26 ; 95 \% \mathrm{CI}:-0.36$ to -0.16 , $\mathrm{p}<0.00001)$ each. The safety analysis indicated that reslizumab was well tolerated. 
Nevertheless, the lack of a NNT for asthma exacerbations, the increase of $\mathrm{FEV}_{1}$ expressed in actual values, and the fact that the improvement of the ACQ did not reach the MCID ( $\geq 0.5$ points) ${ }^{19}$, make the clinical relevance of these results difficult to elucidate.

\section{Anti-interleukin-13 (IL-13) monoclonal antibodies}

Luo et al. ${ }^{17}$ conducted a high confidence SR of RCTs (Fig. 2) to clarify the efficacy and safety of different anti-IL 13 therapies in adult patients with severe asthma. A pooled analysis including four studies (two of lebrikizumab, one of tralokinumab, and one of GSK 679586) shows that anti-IL 13 could not significantly improve the $\mathrm{FEV}_{1}$ compared with placebo. On the other hand, anti-IL 13 therapy significantly decrease asthmatic exacerbations $(\mathrm{RR}=0.55$; 95\% CI: 0.31 to $0.96, \mathrm{p}=0.04$ ). However, the interpretation of this last result should be cautious due to a significant statistical heterogeneity, feasibly derived from factors such as different anti-IL 13 therapies used and the asthmatic population selected. Finally, there was no change in the ACQ score. In terms of safety, there were no significant differences between anti-IL 13 and placebo.

\section{Anti-lgE monoclonal antibody (omalizumab)}

Lai et al. ${ }^{18}$ conducted a high confidence SR (Fig. 2) to determine the efficacy and safety of omalizumab including six long-term trials ( $\geq 52$ weeks) with patients with persistent, uncontrolled, moderate-to-severe allergic asthma in spite of high-dose ICS or ICS plus LABA. Omalizumab-treated patients experienced significantly lower rates of asthma exacerbations compared with placebo during stable clinical conditions $(\mathrm{RR}=0.69 ; 95 \% \mathrm{CI}$ : 0.53 to 0.90). Data from studies with a steroid-reduction phase demonstrated reductions in exacerbation rate that remained significant over periods of 52 weeks $(\mathrm{RR}=0.63 ; 95 \% \mathrm{CI}: 0.55$ to $0.71, \mathrm{p}<0.0001, \mathrm{NNT}=6)$. During the steroid-reduction phase, ICS doses were significantly decreased in omalizumab patients compared with placebo $(\mathrm{RR}=1.86 ; 95 \% \mathrm{CI}$ : 1.51 to 2.29, $\mathrm{p}<0.0001)$. At 52 weeks, the rate of good responses ( $\geq 1.5$ points) of AQLQ scores also favoured omalizumab $(\mathrm{RR}=2.08$; 95\% CI: 1.03 to 4.20, p < 0.04). Omalizumab was well tolerated. However, there was some degree of heterogeneity in the definition of exacerbations between the trials, which may have influenced the pooled effects. Although the results should be interpreted cautiously due to these limitations, data from this SR suggested that long-term use of omalizumab was accompanied with a significant lower rate of asthma exacerbations (six patients had to be treated to prevent one exacerbation during the steroid-reduction phase) and a clinically significant improvement of AQLQ.

\section{MAIN FINDINGS IN COPD}

Six SRs of RCTs met the entry criteria for $\mathrm{COPD}^{20-25}$ : one on the comparison LABA versus $\mathrm{LAMA}^{20}$, one on LABA/LAMA combinations $^{21}$, one on the use of ICS/LABA (i.e. FF/ VI) combination ${ }^{22}$, one on LAMA/LABA (i.e. umeclidinium [UM]/VI) combination ${ }^{23}$, one on phosphodiesterase-4 inhibitor (roflumilast) monotherapy $^{24}$, and one on triple therapy ${ }^{25}$. Characteristics of the SRs are shown in table 3. Four SRs presented a high confidence 
TABLE 2. Characteristics of included systematic reviews on COPD

\begin{tabular}{|c|c|c|c|c|c|c|c|}
\hline $\begin{array}{l}\text { Systematic } \\
\text { review }\end{array}$ & Origen & $\begin{array}{c}\text { Duration } \\
\text { of studies, } \\
\text { weeks }\end{array}$ & $\begin{array}{c}\text { No of } \\
\text { studies/ } \\
\text { patients }\end{array}$ & COPD severity & $\begin{array}{l}\text { Primary } \\
\text { outcome }\end{array}$ & Drugs studied & $\begin{array}{c}\text { Sponsored } \\
\text { by the } \\
\text { pharmaceutical } \\
\text { industry }\end{array}$ \\
\hline Chen et al. ${ }^{20}$ & Taiwan & $12-52$ & $16 / 22,872$ & Moderate to very severe & EX, FEV & LABAs vs. LAMAs & No \\
\hline Rodrigo et al. ${ }^{21}$ & Uruguay & $12-64$ & $23 / 20,185$ & Moderate to very severe & $\mathrm{FEV}_{1}$ & LABA + LAMA & Yes \\
\hline $\begin{array}{l}\text { Rodrigo \& } \\
\text { Neffen }^{22}\end{array}$ & Uruguay & $24-162$ & $6 / 15,515$ & Moderate to very severe & $\begin{array}{l}\text { EX, } \\
\text { FEV }_{1}\end{array}$ & $\mathrm{FF} / \mathrm{VI}$ & No \\
\hline $\begin{array}{r}\text { Rodrigo \& } \\
\text { Neffen }^{23}\end{array}$ & Uruguay & $12-52$ & $11 / 9,609$ & Moderate to severe & $\begin{array}{l}\text { Pulmonary function } \\
\text { Adverse events }\end{array}$ & UM/VI & No \\
\hline Yuan et al. ${ }^{24}$ & China & $12-52$ & $13 / 13,600$ & Moderate to very severe & $\begin{array}{l}\text { EX } \\
\text { FEV }_{1}\end{array}$ & Roflumilast & No \\
\hline $\begin{array}{l}\text { Rojas-Reyes } \\
\text { et al. }{ }^{25}\end{array}$ & Colombia & $12-54$ & $6 / 2,050$ & Moderate to very severe & $\begin{array}{l}\text { EX } \\
\text { Mortality }\end{array}$ & $\begin{array}{l}\text { LABA + Tiotropiuym } \\
+ \text { ICS }\end{array}$ & No \\
\hline
\end{tabular}

EX: exacerbations; FEV1: forced volume in the first second; FF/VI: Fluticasone furoate/vilanterol; ICS: inhaled corticosteroids; LABAs: long-acting beta2-agonists; LAMAs: long-acting muscarinic antagonists; NA: data no available.

AMSTAR's 2 items

\begin{tabular}{|c|c|c|c|c|c|c|c|c|c|c|c|c|c|c|c|c|}
\hline \multirow{2}{*}{\multicolumn{17}{|c|}{ Chen et al. ${ }^{20}$}} \\
\hline & & & & & & & & & & & & & & & & \\
\hline \multicolumn{17}{|l|}{ Rodrigo et al. ${ }^{21}$} \\
\hline \multicolumn{17}{|l|}{ Rodrigo \& Neffen²2 } \\
\hline \multicolumn{17}{|l|}{ Rodrigo \& Neffen 23} \\
\hline Yuan et al.24 & & & & & 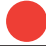 & & 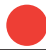 & & 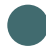 & 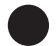 & ก & 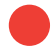 & 0 & 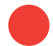 & & 0 \\
\hline jas-Reyes et al. ${ }^{25}$ & & & & & & & 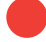 & & ret & & 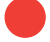 & & & & & \\
\hline
\end{tabular}

Figure 3. Methodological quality assessment of selected COPD systematic reviews using the Measurement Tool to Assess systematic Reviews (AMSTAR 2) tool (with permission form Egger M et al. ${ }^{\text {) } . ~ F o r ~ f u r t h e r ~ i n f o r m a t i o n ~ s e e ~ F i g ~} 2$.

of the results ${ }^{21-23.25}$, one a low confidence ${ }^{20}$, and one a critically low confidence ${ }^{24}$ (Fig. 3).

\section{Long-acting $\beta_{2}$-agonists versus long-acting muscarinic antagonist}

Chen et al. ${ }^{20}$ performed a low confidence SR (Fig. 3) to evaluate the comparative efficacy and safety of LAMAs (tiotropium, umeclidinium, glycopyrronium and aclidinium) versus LABAs (salmeterol, formoterol, indacaterol, vilanterol, and olodaterol) in stable COPD patients. Treatment with LAMAs significantly reduced COPD exacerbations, compared with non-ultra LABAs (formoterol and salmeterol) $(\mathrm{OR}=0.84 ; 95 \% \mathrm{CI}: 0.77$ to $0.92, \mathrm{p}<0.0001$, NNT $=28)$. However, there was no statistical 
difference between LAMAs versus ultra LABAs (indacaterol and olodaterol). There were no significant differences in $\mathrm{FEV}_{1}$, transitional dyspnoea index (TDI), and the St. George's Respiratory Questionnaire (SGRQ) score between LAMAs and LABAs. Although the incidence of any adverse event was significantly higher in the patients treated with LABAs, the results of serious adverse events were not statistically significant between the LAMAs and LABAs groups. Although this SR suggests a slight advantage of LAMAs in terms of exacerbations (only against non-ultra LABAs), there were no significant differences in lung function, symptom score and health status. So, the most appropriate initial choice of bronchodilator in patients with stable COPD seems still undetermined.

\section{Long-acting $\beta_{2}$-agonists/long-acting muscarinic antagonists combinations}

Rodrigo et al. ${ }^{21}$ conducted a high confidence SR (Fig. 3) including 23 RCTs to compare the efficacy and safety of LABA/LAMA combinations (only approved doses) with LAMA or LABA/ICS (salmeterol/fluticasone) in adults with stable moderate-to-very-severe COPD. Sponsored by the pharmaceutical industry. LABA/LAMA significantly improved the likelihood of achieving an MCID $(\geq 100 \mathrm{~mL})$ in trough $\mathrm{FEV}_{1}$ versus both LAMA and LABA/ICS (NNT $=8$, and NNT $=6$, respectively). Significant improvements in peak $\mathrm{FEV}_{1}$ were also observed for LABA/LAMA treatment versus both comparators $(\mathrm{MD}=110 \mathrm{~mL}$ and $120 \mathrm{~mL}$, respectively). LABA/LAMAtreated patients were more likely to achieve a MCID in TDI ( $\geq 1$ unit) [27-28] $(\mathrm{NNT}=19)$ and in SGRQ scores $(\mathrm{NNT}=16)$ versus LAMA but not versus LABA/ICS. Although there were insufficient data to conduct a metaanalysis on the effect of treatment on prospectively collected COPD exacerbation rates in LABA/LAMA versus LAMA (only one study), LABA/LAMA significantly reduced the rate of moderate to severe exacerbations in comparison with LABA/ICS $(\mathrm{RR}=0.82$; 95\% CI: 0.75-0.91, p < 0.001). However, the authors did not report the NNT for this estimate. There was significantly less incidence of pneumonia in the LABA/ LAMA group versus LABAs/ICS $(\mathrm{NNT}=84)$. Neither the incidence of severe adverse events nor cardiovascular-related events were significantly different between the LABA/LAMA and LABA/ICS groups. Thus, this $S R$ provides evidence that LABA/LAMA offer superior efficacy to LAMA and LABA/ICS (mainly in lung function) in patients with stable moderate-to-very severe COPD. The efficacy on other outcomes appears as less consistent and of lesser magnitude. Additional studies are required to clarify the effect of LABA/LAMA on COPD exacerbations.

\section{Inhaled corticosteroid/long-acting $\beta_{2}$-agonists (fluticasone furoate/ vilanterol)}

Rodrigo and Neffen ${ }^{22}$ conducted a high confidence SR (Fig. 3) to assess efficacy and safety of the use of FF/VI combination versus each agent alone, for the treatment of patients with severe-to-very-severe stable COPD. The authors found that FF/VI was associated with a significant increase in $\mathrm{FEV}_{1}$ compared with VI (MD $=45 \mathrm{ml} ; 95 \%$ CI: 27 to $62, \mathrm{p}=0.0001)$. On the contrary, there was no difference in peak $\mathrm{FEV}_{1}$. FF/VI significantly reduced the number of subjects with at least one moderate-severe 
exacerbation ( $\mathrm{RR}=0.83$; 95\% CI: 0.78 to 0.88 , $\mathrm{p}=0.0001, \mathrm{NNT}=21)$. Patients receiving FF/VI presented a significant increased rate of pneumonia compared with VI $(\mathrm{NNT}=57)$. FF/VI significantly increased $\mathrm{FEV}_{1}$ peak and trough compared with FF (MD = 130 and 100 respectively), and significantly decreased COPD exacerbations ( $\mathrm{RR}=0.84 ; 95 \% \mathrm{CI}: 0.78$ to 0.90 , $p=0.00001$, NNT $=26$ ). There were no significance differences in the rate of severe adverse events and pneumonia. In summary, FF/VI was related to a clinically relevant increase in $\mathrm{FEV}_{1}$ only when it was compared with FF (MCID $\geq 100 \mathrm{ml}$ ) but not with VI. Also, FF/VI was associated with moderate decreases of the rate of COPD exacerbations compared with VI and FF (one in every 21-26 patients treated). Finally, FF/VI was also associated with an increased rate of pneumonia in comparison to VI.

\section{Long-acting muscarinic antagonist/ long-acting $\beta_{2}$-agonists (umeclidinium/vilanterol)}

Rodrigo and Neffen ${ }^{23}$ performed a high confidence SR (Fig. 3) to assess the efficacy and safety of UM/VI combination compared with its mono-components, tiotropium, or LABA/ ICS for the treatment of stable COPD. UM/VI provided superior improvements in trough $\mathrm{FEV}_{1}$ compared with UM, VI, tiotropium, and FP/SAL (60, 110, 90, and $90 \mathrm{ml}$, respectively). $\mathrm{UM} / \mathrm{VI}$ patients were $22 \%(\mathrm{NNT}=9), 41 \%$ $(\mathrm{NNT}=6)$, and $28 \%(\mathrm{NNT}=8)$ more likely to achieve a MCID in trough $\mathrm{FEV}_{1}(>100 \mathrm{~mL})$ in comparison of UM, VI, and tiotropium patients. Also, UM/VI had a greater likelihood of demonstrating a MCID on the TDI compared with UM and VI (NNT = 14 and 10, respectively). UM/VI significantly reduced the risk of COPD exacerbations compared with $\mathrm{UM}$ and VI (NNT = 42 and 41, respectively). There were no significant differences between $\mathrm{UM} / \mathrm{VI}$ and tiotropium with respect to dyspnoea, health status, or risk of COPD exacerbations. Regarding safety issues, the incidence of adverse events, serious events, cardiovascular events, and mortality was similar across treatments. Thus, UM/VI showed superior efficacy in lung function compared with its mono-components, tiotropium, and FP/combination in patients with moderate-to-severe COPD. The effect on COPD exacerbations was modest (one in more than 40 patients). Of note, UM/VI was not superior to tiotropium in dyspnoea, health status, or risk of COPD exacerbations.

\section{Phosphodiesterase-4 inhibitor (roflumilast)}

Yuan et al. ${ }^{24}$ performed a critically low confidence SR (Fig. 3) to evaluate the clinical effects and safety of roflumilast in the treatment of stable COPD. The use of roflumilast reduced COPD exacerbations in comparison to placebo $(\mathrm{OR}=0.82 ; 95 \%$ CI: 0.75 to $0.9, \mathrm{p}<0.0001$, $\mathrm{NNT}=32$ ). The mean $\mathrm{FEV}_{1}$ change from baseline of patients who received roflumilast compared with placebo was $65 \mathrm{ml}$, but with a very important heterogeneity. Finally, the overall incidence of adverse drug events was $54.2 \%$ in the roflumilast group and $48.2 \%$ in the placebo group (OR $=1.36 ; 95 \%$ CI: 1.13 to 1.65$)$. The most common adverse event reported with roflumilast was diarrhoea. In addition to the heterogeneity of the studies and the high risk of bias, the clinical relevance of these results looks modest, as they do not reach the MCID in the main outcomes ${ }^{26-27}$. 


\section{Triple therapy}

Rojas-Reyes et al. ${ }^{25}$ in a high confidence SR (Fig. 3) evaluated the efficacy and safety of tiotropium/LABA/ICS combination (triple therapy) compared with tiotropium or LABA/ICS in stable moderate-to-very-severe COPD patients. When compared with tiotropium, triple therapy did not show significant differences in mortality nor in the all-cause hospitalizations. The effect on exacerbations was heterogeneous among trials and was not meta-analysed. Health-related quality of life measured by SGRQ showed a statistically significant improvement in total scores with the use of triple therapy in comparison with tiotropium (MD $=-3.33$; 95\% CI: -4.72 to $-1.94, \mathrm{p}<0.0001)$. Triple therapy showed a significant increase in lung function, although average benefit was small $(\mathrm{MD}=60 \mathrm{ml})$. There were no significant statistical differences in adverse events, serious adverse events and pneumonia. Because only one study presented the comparison triple therapy versus LABA/ICS, no conclusion could be drawn. The available evidence was insufficient to support the benefit of triple therapy on tiotropium or LABAs/ICS in stable COPD patients*.

\section{CLINICAL RELEVANCE, STRENGTHS AND SHORTCOMINGS*}

The aim of this review was to summarise the most updated information from SRs on pharmacological management of adults with asthma and COPD under stable clinical conditions. We analysed a set of SRs of high

\footnotetext{
* The very recent RCTs with single-inhaler triple devices have not been considered in this review.
}

methodological quality. Nevertheless, our analysis found particularly difficult to extract clear messages that can be applied in clinical practice. Thus, a significant number SRs assumed that the mere presence of a statistically significant difference in a particular outcome automatically transforms it into a clinically relevant difference. Thus, not infrequently, SRs do not report data regarding to MCID or NNT of main estimates. Although we should be aware that the calculation and interpretation of the NNT depend on the characteristics of a given study, namely the design and outcomes, and is specific to a given comparison, NNT helps to quantify the magnitude of effects of medical interventions in an absolute scale, therefore bringing added value to decisions on drug utilization for clinicians ${ }^{8}$.

The main findings that arise from this study can be summarised as follows:

\section{Asthma}

1) There is insufficient information to determine whether once-daily FF/VI was better or worse than twice-daily FP/SAL in terms of efficacy. 2) Similarly, there is insufficient data to evaluate the evidence for stepping down ICS treatment in adults with well-controlled asthma receiving moderate to high dose of ICS. 3) Tiotropium is superior to placebo in patients with moderate-to-severe asthma who are not adequately controlled with low to moderate ICS or high doses of ICS plus LABAs. 4) Although anti-IL5 improved significantly pulmonary function and health status, and reduced exacerbations, it is controversial to interpret these findings given the 
heterogeneity of the asthmatic sample, and the fact that MCID was not reached. Data does not support the superiority of any of the anti-IL5 therapies. 5) Mepolizumab significantly reduces the rate of severe exacerbations in patients with severe eosinophilic asthma. However, the impact looks rather low to moderate. 6) The lack of a NNT for asthma exacerbations, the increase of $\mathrm{FEV}_{1}$ expressed in actual values, and the fact that the improvement of the ACQ did not reach the MCID make the clinical relevance of reslizumab difficult to elucidate. 7) Analysis of anti-IL 13 therapies presented the limitations derived from a very heterogeneous asthmatic population, as well as the different drugs tested. 8) Omalizumab-treated patients experienced statistical and probably clinical significant reductions of asthma exacerbations during the stable and steroid-reduction phases.

\section{COPD}

1) Although evidence suggests a slight advantage of LAMA in terms of exacerbations against non-ultra LABA, there were no significant differences in lung function, symptom score and health status. So, the initial choice of a bronchodilator in patients with stable COPD still remains unsettled. 2) LABA/LAMA combinations presented superior efficacy (pulmonary function, dyspnoea, and health related quality of life) and comparable safety to LAMA or LABA/ICS in patients with stable moderate-to-very severe COPD. 3) FF/VI was associated with a moderate decrease of COPD exacerbations, and also related to a clinically relevant increase in $\mathrm{FEV}_{1}$ compared with FF but not with VI. However, FF/VI was related to an increased rate of pneumonia in comparison to VI. 4) UM/VI showed superior efficacy (lung function and dyspnoea) compared with its mono-components, tiotropium, and FP/SAL combination in patients with moderate-to-severe COPD. 5) Roflumilast significantly reduced COPD exacerbation and increase pulmonary function in comparison with placebo. However, the clinical relevance of these results appears modest. 6) Evidence results insufficient to support the benefit of triple therapy compared with tiotropium or LABAs/ICS in stable COPD patients.

\section{CONCLUSIONS}

Data from this review suggest that there is an important body of evidence supporting the clinical use of specific pharmacological treatments as tiotropium and omalizumab in asthma and LABA/LAMA and ICS/LABA combinations in COPD. On the other hand, the evidence from a substantial part of the SRs analysed is uncertain or non-existent, thus not allowing to extract clear messages that can be applied in clinical practice. This last category includes important topics such as the comparison of once-daily FF/VI versus twice daily FP/SAL and the withdrawal of ICS treatment in asthma, or the comparison LABA versus LAMA and triple therapy in COPD.

\section{CONFLICT OF INTEREST}

In the last three years, Dr. Gustavo J. Rodrigo has participated as a lecturer, speaker and advisor in scientific meetings and courses under the sponsorship of Air Products \& Chemicals Inc., Boehringer Ingelheim, GlaxoSmithKline, and Novartis. 


\section{FUNDING SOURCE}

\section{No sponsorship from institutions or pharma- ceutical industry was provided to conduct this study.}

\section{REFERENCES}

1. Global, regional, and national deaths, prevalence, disability-adjusted life years, and years lived with disability for chronic obstructive pulmonary disease and asthma, 1990-2015: a systematic analysis for the Global Burden of Disease Study 2015. Lancet Respir Med. 2017;5:691-706.

2. To T, Stanojevic S, Moores $\mathrm{G}$ et al. Global asthma prevalence in adults: findings from the cross-sectional world health survey. BMC Public Health. 2012:12:204.

3. MEDLINE ${ }^{\circledR}$ Number of Citations to English Language Articles; Number of Citations Containing Abstracts (as of mid - December 2016). Available from https://www.nlm.nih.gov/bsd/medline_lang_distr.html. [Accessed November 1 2017].

4. Chalmers I, Hedges LV, Cooper H. A brief history of research synthesis. Eval Health Prof. 2002;25:12-37.

5. Bastian H, Glasziou P, Chalmers I. Seventy-five trials and eleven systematic reviews a day: How will we ever keep up? PLoS Med. 2010;7:e1000326.

6. Cook DJ, Mulrow CD, Haynes RB. Systematic reviews: Synthesis of best evidence for clinical decisions. Ann Intern Med. 1997;126:376-80.

7. Egger M, Smith GD. Metaanalysis. Potentials and promise. BMJ. 1997;315: 1371-4

8. Higgins JPT, Green S, eds Cochrane handbook for systematic reviews of interventions. Version 5.1.0. New York, NY: Wiley; 2011. The Cochrane Collaboration. http://handbook.cochrane.org/. Accessed November 2, 2017.

9. Cook DJ, Greengold NL, Ellrodt AG, Weingarten SR. The relation between systematic reviews and practice guidelines. Ann Intern Med. 1997;27:210-6.

10. Shea BJ, Reeves BC, Wells G et al. AMSTAR 2: a critical appraisal tool for systematic reviews that include randomised or non-randomised studies of healthcare interventions, or both. BMJ. 2017; 358:j4008.

11. Dwan K, Milan SJ, Bax L, Walters N, Powell C. Vilanterol and fluticasone furoate for asthma. Cochrane Database Syst Rev. 2016;9: CD010758.

12. Crossingham I, Evans DJW, Halcovitch NR, Marsden PA. Stepping down the dose of inhaled corticosteroids for adults with asthma. Cochrane Database Syst Rev. 2017; 2: CD011802.

13. Rodrigo GJ, Castro-Rodríguez JA. What is the role of tiotropium in asthma? A systematic review with meta-analysis. Chest. 2015;147:388-96.
14. Wang FP, Liu T, Lan Z, Li SY, Mao H. Efficacy and safety of anti-interleukin-5 therapy in patients with asthma: a systematic review and meta-analysis. PLoS One. 2016;11:e0166833.

15. Yancey SW, Ortega HG, Keene ON et al. Meta-analysis of asthma-related hospitalization in mepolizumab studies of severe eosinophilic asthma. J Allergy Clin Immunol. 2017;139:1167-75.

16. Li J, Wang F, Lin C et al. The efficacy and safety of reslizumab for inadequately controlled asthma with elevated blood eosinophil counts: A systematic review and meta-analysis. J Asthma. 2017;54:300-7.

17. Luo J, Liu D, Liu CT. The efficacy and safety of antiinterleukin 13, a monoclonal antibody, in adult patients with asthma. A systematic review and meta-analysis. Medicine. 2016; 95:e2556.

18. Lai $\mathrm{T}$, Wang $\mathrm{S}, \mathrm{Xu} \mathrm{Z}$ et al. Long-term efficacy and safety of omalizumab in patients with persistent uncontrolled allergic asthma: a systematic review and meta-analysis. Sci Rep. 2015;5:8191.

19. Reddel HK, Taylor DR, Bateman ED et al. American Thoracic Society documents. An official American Thoracic Society/European Respiratory Society statement: asthma control and exacerbations. Standardizing endpoints for clinical asthma trials and clinical practice. Am J Respir Crit Care Med. 2009;180:59-99.

20. Chen WC, Huang $\mathrm{CH}$, Sheu $\mathrm{CC}$ et al. Long-acting beta2-agonists versus long-acting muscarinic antagonists in patients with stable COPD: A systematic review and meta-analysis of randomized controlled trials. Respirology. 2017;22:1313-19.

21. Rodrigo GJ, Price D, Anzueto A et al. LABA/LAMA combinations versus LAMA monotherapy or LABA/ICS in COPD: a systematic review and meta-analysis. Int J Chron Obstruct Pulmon Dis. 2017;12:907-22.

22. Rodrigo GJ, Neffen H. A systematic review with meta-analysis of fluticasone furoate/vilanterol combination for the treatment of stable COPD. Pulm Pharmacol Ther. 2017;42:1-6.

23. Rodrigo GJ, Neffen H. A systematic review of the efficacy and safety of a fixed-dose combination of umeclidinium and vilanterol for the treatment of COPD. Chest. 2015;148: 397-407.

24. Yuan L, Dai X, Yang M, Cai Q, Shao N. Potential treatment benefits and safety of roflumilast in COPD: a systematic review and meta-analysis. In J Chron Obstruct Pulmon Dis. 2016;11:1477-83.

25. Rojas-Reyes MX, García Morales OM, Dennis RJ, Karner C. Combination inhaled steroid and long-acting beta2-agonist in addition to tiotropium versus tiotropium or combination alone for chronic obstructive pulmonary disease. Cochrane Database Syst Rev. 2016;6: CD008532.

26. Cazzola M, MacNee W, Martinez FJ et al. Outcomes for COPD pharmacological trials: from lung function to biomarkers. Eur Respir J. 2008;31:416-68.

27. Jones PW, Beeh KM, Chapman KR et al., Minimal clinically important differences in pharmacological trials, Am J Respir Crit Care Med. 2014;189: 250-5.

28. Donohue JF. Minimal clinically important differences in COPD lung function. COPD. 2005;2:111-24. 